\title{
Prediksi Kebutuhan Data Mahasiswa Untuk Kuliah Daring Kondisi Covid-19 Di Jurusan Teknik Elektro Universitas Mataram
}

\section{Prediction of Student Data Needs for Online Lectures Covid-19 Conditions in the Department of Electrical Engineering, University of Mataram}

\author{
Made Sutha Yadnya*1, Ni Luh Sinar Ayu Ratna Dewi ${ }^{2}$, Sudi Maryanto Al Sasongko ${ }^{1}$, \\ Rosmaliati $^{1}$, Abdulah Zainuddin ${ }^{1}$ \\ ${ }^{1}$ Jurusan Teknik Elektro, Fakultas Tenik, Universitas Mataram \\ ${ }^{2}$ Jurusan Dharma Duta Prodi Ilmu Komunikasi Hindu, IAHN Gde Pudja Mataram \\ *corresponding author,email msyadnya@unram.ac.id
}

Manuscript received: 25-11-2021. Accepted: 21-12-2021

\begin{abstract}
ABSTRAK
Pada kondisi covid-19 perkuliahan di Jurusan Teknik Elektro Universitas Mataram berubah dari proses tatap muka menjadi via Internet. Lonjakan kebutuhan ada akan sangat meningkat sangat tajam. Penggunaan data pada awalnya yang disediakan oleh Universitas Mataram dengan menggunakan jaringan hotspot bersifat gratis berubah menjadi beban pada dosen serta mahasiswa. Penelitian ini dilakukan dengan pengambilan sampel matakuliah wajib umum, matakuliah wajib elektro, dan matakuliah wajib keahlian. Sebaran variasi mahasiwa berdomisili di Kota Mataram dan posisi disekitarnya, Pulau Lombok, dalam NTB dan luar NTB. Hasil yang diperoleh adalah sebagai berikut: mahasiswa yang masih bertahan di Kota Mataram adalah 17\% (10,5GB), pulau Lombok $48 \%$ (8,1GB), luar pulau Lonbok $27 \%$ (4,8GB), dan luar NTB 8\% (15GB).
\end{abstract}

Kata kunci: covid-19; perkuliahan; daring

\begin{abstract}
In the covid-19 condition, lectures at the Department of Electrical Engineering, Mataram University changed from a face-to-face process to via the Internet. $T$ here will be a very sharp increase in demand. The use of data initially provided by the University of Mataram using a free hotspot network turned into a burden on lecturers and students. This research was conducted by sampling, general compulsory subjects, compulsory electrical courses, and compulsory expertise subjects. The distribution of variations of students domiciled in the City of Mataram and the other place coverage Lombok Island, within NTB and outside NTB. The results obtained are as follows: students who still survive in Mataram City are 17\% (10.5 GB), Lombok Island 48\% (8.1 GB), outside Lonbok Island $27 \%$ (4.8 GB), and outside NTB 8\% (15 GB).
\end{abstract}

Keyword : covid-19; lectures; online 


\section{PENDAHULUAN}

Perubahan proses pendidikan dan pengajaran telah berubah akibat adanya pandemi covid yang melanda seluruh dunia. Pengajaran yang biasaya adalah tatap muka menjadi komunikasi dengan utamamya Internet. Penggunaan data pada awalnya yang disediakan oleh Universitas Mataram dengan menggunakan jaringan hotspot bersifat gratis berubah menjadi beban pada dosen serta mahasiswa. Pada kondisi covid perkuliahan di Jurusan Teknik Elektro Universitas Mataram berubah dari proses tatap muka menjadi via Internet. Lonjakan kebutuhan ada akan sangat meningkat sangat tajam.

Kajian Kebutuhan Data Secara Nyata Untuk Pendidikan dan Pengajaran Belum Ada di Jurusan Teknik Elektro Universitas Mataram. Posisi Mahasiswa dalam menakukan kuliah sangat variatif. Pengaksessan terhadap tujuan informasi juga bervariatif. Variasi Akses : Daring Unram (blanded), WA Group \& Google Form, Zoom, Google Classroom, BB,Surfing Pendidikan, Sosial Media,Game OnLine. Variasi Posisi :Kota Mataram, Pulau Lombok, NTB, Luar NTB.

\section{BAHAN DAN METODE}

Dalam memprediksi kebutuhan data mahasiswa untuk pembelajaran di Jurusan Teknik Elektro makalah ini mengunakan metode yang paling umum dibunakan dalam memprediksi yaitu Moving Average (MA) atau dikenal degan rata-rata bergerak. Prediksi ini dengan pemodelan data pada klaster hasil merata-ratakan data dengan beberapa nilai rerata dengan variasi tertentu. Pada penelitian tahun 2008 didapatkan Penggunaan metode untuk menentukan ramalan pada periode yang akan datang memerlukan data historis atau time series selama jangka waktu tertentu.. Semakin panjang jangka waktu moving average, makan niali efek rerata akan semakin terlihat dalam ramalan atau menghasilkan moving average yang semakin mendekati data yang akan terjadi. Hal ini dipergunakan dalam data menunjukan data yang terus bergerak sesuai dengan klas asusmsi awal. Langkah yang dilakukan dalam penyelesaian menggunkan persamaan MA (Yadnya,2008):

$M A=\frac{A 1+A 2+A 3+\cdots . A n}{N}$

definisi persamaan adalah :

MA $=$ Moving Average

$\mathrm{A} 1=$ data pertama, A2 data kedua, A3 data ketiga, An data ke-n dengan $\mathrm{N}$ sebagai jumlah data yang tersedia.

Metode dengan signikikan tinggi telah dipergunakan untuk memprediksi trend yaitu autoregresive moving average, memebrlukan data sampel yang sangat besar dengan time series yang lama untuk menghasilkan nilai yang stabil sesuai orde (Yadnya,2008c):

Penggunaan metode sebagai berikut : Data yang diperoleh diurutkan dari data yag terkecil sampai data yang terbesar. Data yang mempunyai trend yang signifikan dibutkan klas baru dengan nilai rerata baru sebagai patokan. Penetuan trend data perlu diasumsikan dalam urutan data sesuai distribusi yang diperoleh (Yadnya, 2009). Pembuatan data baru dengan menetukan rerata pengolahan data awal sampai ketemu klas sehigga pembangkitan dari variasi dalam satu klas dapat dikemukakan dalam satu prediksi. Peluang melakukan presiksi 
dengan pembangkitan dari distutbusi data sehiggan data baru sebagai hasil prediksi. Metode ini dipergunakan sebagai dasar suatu data yang diinginkan menjadi stabil stabil dengan kondisi asusmsi dalam prediksi mempunyai keseimbangan data. Tiga langkah yang perlu dilakukan yaitu : pemulusan eksponensial, pembuatan trend, serta urutan data estimasi, sehinggan untuk mendapatkan nilai dari suatu prediksi yang sesuai dengan pengambilan data (Bactiar,2017).

1. Pemulusan Eksponensial

$$
A_{t}=\alpha \frac{Y_{t}}{S_{t-L}}+(1-\alpha)\left(A_{t-1}+b_{t-1}\right)
$$

$\mathrm{L}$ :panjang dari satu ururan

2. Pembuatan trend yang halus

$$
b_{t}=\gamma\left(A_{t}-A_{t-1}\right)+(1-\gamma) b_{t-1}
$$

3. Urutan data Estimasi :

$$
S_{t}=\beta \frac{Y_{t}}{A_{t}}+(1-\beta) S_{t-L}
$$

Nilai prediksi

$$
\hat{Y}_{t+p}=\left(A_{t}-p b_{t}\right) S_{t-L+p}
$$

Dimana

$\mathrm{L}=$ panjang dari satu ururan

$\mathrm{B}=$ komponen trend

$\mathrm{I}=$ faktor penyesuaian urutan

Hasil nilai yang diprediksi merupakan, pembeajaran data yang didapat dengan trend yang diperoleh sehingga data tersebut membuat urutan data baru dengan membangkitkan data rata-rata yang sudah diperoleh sebelummya. Nilai data yang mempunyai kondisi yang sangat timplang perlu ada klasifikasi yang harus dibuat terlebih dahulu dengan membagi pergerakan serta urutan data sesuai dengan pembangkitan variasi data atau standar deviasi yang sudah diperoleh. Trend data yang naik maupun turun dapat dihaluskan/ dimuluskan sesuai dengan kondisi data serta pembaharuan data untuk membangkitkan data yang baru (Yadnya,2018).

Keakuratan prediksi dengan data yang stabil memberikan keputuasn yang terbaik untuk memberikan rekomendasi dengan klasifikasi. Penentuan klasifikasi terbentuk dari data terdahulu sehingga hasil menjadi akurat. Metode prediksi pernah digunakan untuk umum dan bisnis contoh digunakan untuk prediksi produksi garmen hasil lebih akurat jiika data yang diolah libih banyak hasil lebih akurat (Rachman, 2018).

Setelah itu, hasil maserasi disaring sehingga diperoleh maserat. Maserat etanol yang diperoleh kemudian dipekatkan menggunakan evaporator dengan suhu $40^{\circ} \mathrm{C}$. Ekstrak kental dilarutkan dengan menggunakan DMSO 50\% sesuai konsentrasi untuk pengujian yaitu 20\%, 40\%, 60\%, dan 80\% (Handrianto, 2018). 


\section{HASIL DAN PEMBAHASAN}

Data yang diperoleh Penelitian ini dilakukan dengan pengambilan sampel matakuliah wajib umum, matakuliah wajib elektro, dan matakuliah wajib keahlian. Sebaran variasi mahasiwa berdomisili di Kota Mataram, Pulau Lombok, dalam NTB dan luar NTB. Kondisi mahasiswa aktif di JTE adalah :560 mahasiswa dan sampel yang diambil 101 mahasiswa. Data diambil pada semester genap 2019/2020 dengan instrument google form untuk mata kuliah Wajib Dasar (42 mahasiswa), Wajib Elektro (38 mahasiswa) dan Wajib Konsentrasi (22 mahasiswa).

Hasil perhitungan data untuk prediksi pada Gambar 1 merupakan data inputan awal dengan dengan mengelompokkan kebutuhan data tertinggi sampai terendah. Data tersebut menghasilkan veriasi dan standar deviasi untuk pembangkitan data prediksi sesuai trend data yang dihasilkan dari kwesener dalam bentuk google form. Mahasiswa yang mempunyai kebiasaan dengan on line tinggi sering menggakses game on line dan sosial media. Ternyata data yang dihasilkan mempunyai effek penggunaan data sesuai dengan posisi dari mahasiswa mengakses data pembelajaran meggunakan metode dalam jaringan atau daring, hasil tersebut dapat dilihat pada Gambar 2. Sehinga dengan asumsi prediksi data yang diperoleh seperti Gambar 3, yang memberikan gambaran kebutuhan data yang diperlukan kebutuhan data internet oleh mahasiswa. Pada akhir semester diberikan suatu pertnyaan dengan pemilihan menggunakan tatap muka langsung atau daring mengahsilkan $73 \%$ ingin tatap muka langsung, $18 \%$ menggunakan daring, dan sisanya tidak memilih satu antara 2 tersebut

Masa covid masih tetap berlangsung maka diperlukan peningkatan kualitas serta kwantitas dari jaringan untuk pengaksesan internet Kebutuhan utama untuk pendidikan dan pengajaran adalah kubutuhan tatap muka. Pembelajaran dengan model simulasi terus dikembangkan. Prasarana untuk jaringan internet perlu ditingkatkan atau di remajakan utama pada kapasitas server baik jalur maupun penyimpanan data.

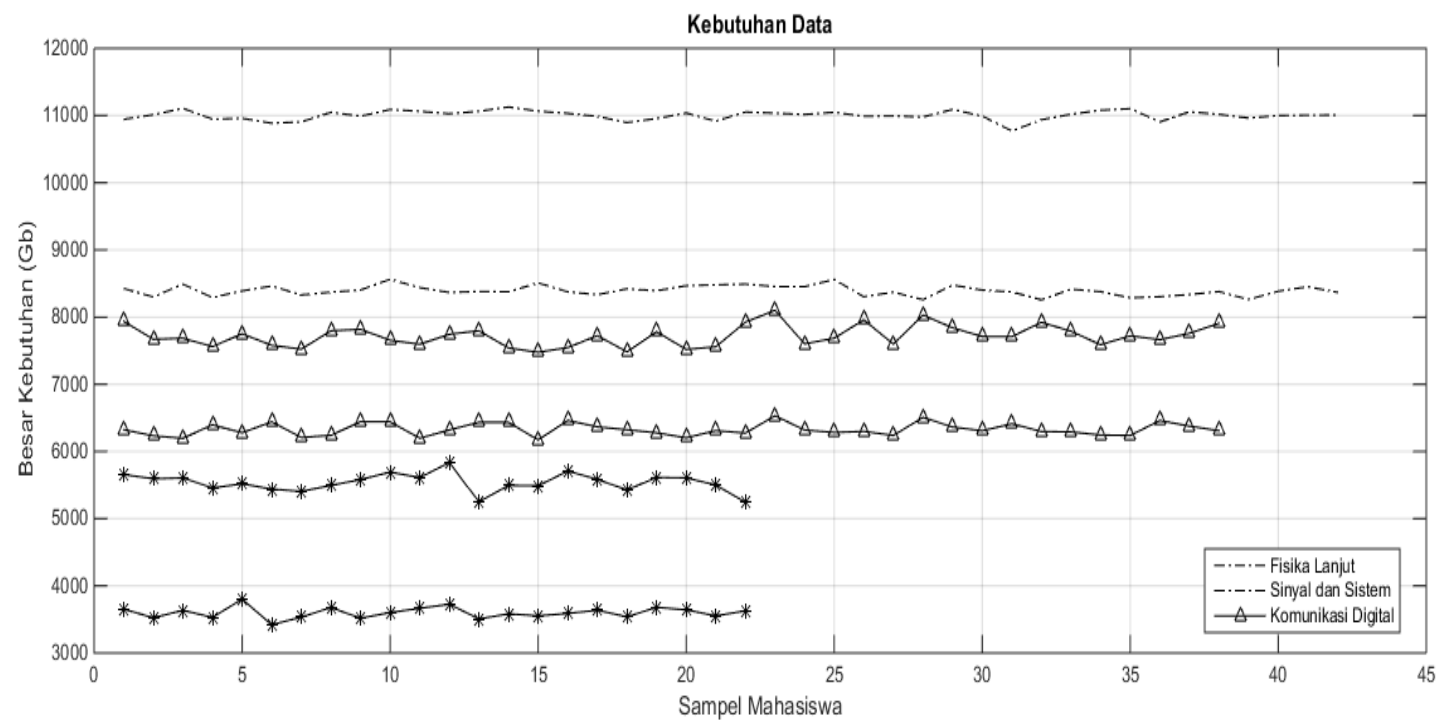

Gambar 1 Kalsifikasi Kebutuhan data dengan menetukan terrendah dengan tertinggi, 


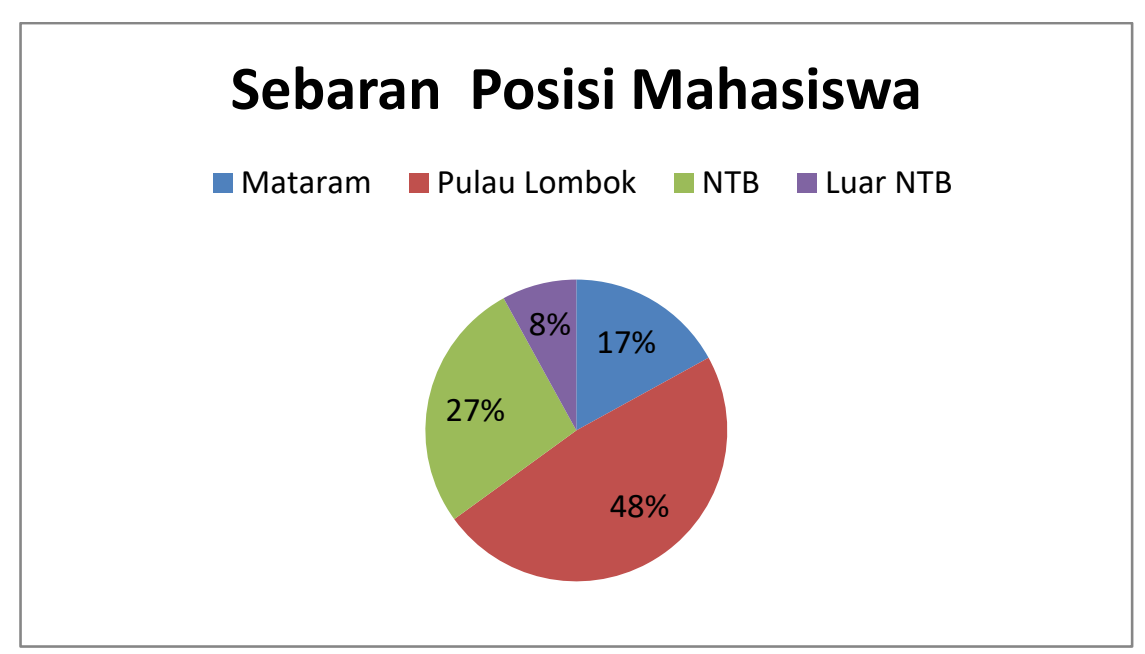

Gambar 2 Sebaran Posisi Mahasiswa

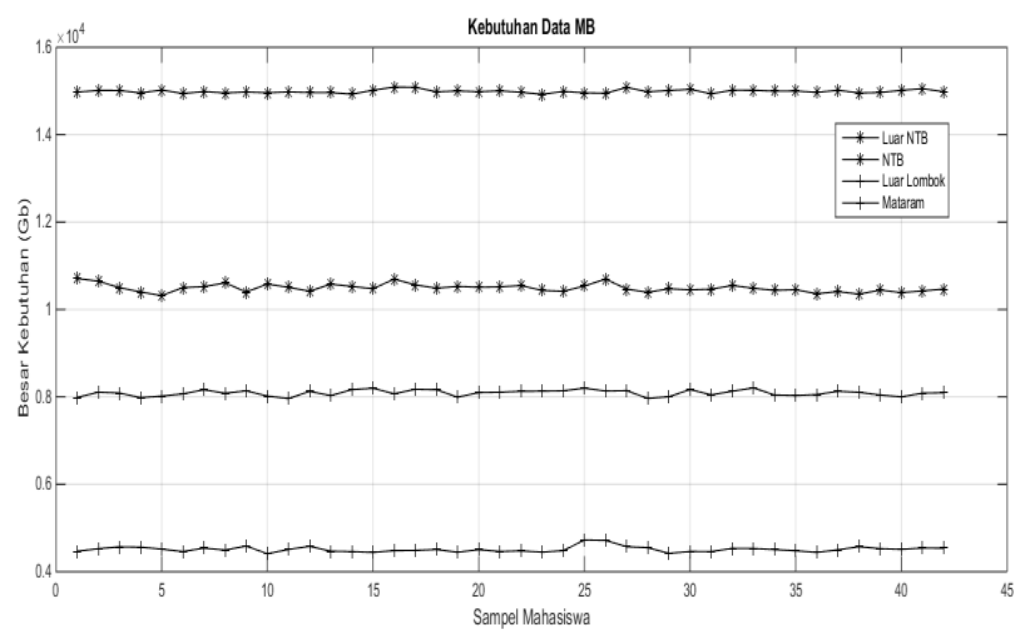

Gambar 3. Hasil Prediksi menggunakan kebutuhan data Internet

\section{KESIMPULAN}

Hasil yang diperoleh dengan pengambilan sampel matakuliah wajib umum, matakuliah wajib elektro, dan matakuliah wajib keahlian. Sebaran variasi mahasiwa berdomisili di Kota Mataram, Pulau Lombok, dalam NTB dan luar NTB. Hasil yang diperoleh adalah sebagai berikut: mahasiswa yang masih bertahan di Kota Mataram adalah 17\% (10,5GB), pulau Lombok 48\% (8,1GB), luar pulau Lonbok $27 \%$ (4,8GB), dan luar NTB $8 \%(15 G B)$.

\section{Ucapan Terimakasih}

Pemulis memberikan ucapan terimakasih kepada Pengambil Kebijakan Jurusan Teknik Elektro Universitas Mataram. Pak Sar'I pada Bidang Administrasi Jurusan Teknik Elektro. Pak Cahyadi bidang surat mengurat , Nyoman Putra untuk menginput data, 
Mahasiswa (Suci RY, Viviana, dan Alive) serta semua responden pada Jurusan Teknik Elektro Universitas Mataram yang telah mengisi google form.

\section{DAFTAR PUSTAKA}

Bactiar RY. 2017, Peramalan dengan metode Single Moving Average dan Mencari Nilai MSE, Repository ITS

Rachman R, (2018) Penerapan Metode Moving Average Dan Exponential Smoothing Pada Peramalan Produksi Industri Garment, Jurnal Informatika 5(2):211-220, DOI: 10.31311/ji.v5i2.3309, STMIK Nusa Mandiri Jakarta

Yadnya MS, A Mauludiyanto, G Hendrantoro (2008),ARMA modelling from rain rate measurement to simulation communication channel modelling for millimeter wave in Surabaya. 6th Proceeding Kumamoto University .

Yadnya MS, Reni K, Hendrantoro G, 2009, Pembangkitan Curah Hujan dengan model MA (Moving Average) dari Hasil Pengukuran di Surabaya. ICAST 2009

Yadnya MS, A Mauludiyanto, G Hendrantoro 2008c, Statistical of Rain Rate for Wireless Channel Communication in Surabaya", WOCN 5-7 May 2008 Surabaya-Indonesia, IEEE Conference.

Yadnya MS., Sudiarta IW 2018, "Synthesis of 4G outdoor femtocells under rain conditions in Mataram” AIP Conference Proceedings pp 2043-2048 